\title{
STUDY ON CHARACTERISTICS AND CAUSE OF SAND WAVES IN THE KANMON WATERWAY
}

\author{
Masaru Yamashiro, Kyushu University, yamashiro@civil.kyushu-u.ac.jp \\ Kosaku Oka, Kyushu University, 2TE17283E@s.kyushu-u.ac.jp \\ Noriaki Hashimoto, Kyushu University, hashimoto-n@civil.kyushu-u.ac.jp \\ Yasuyuki Nakagawa, Kyushu University, y.nakagawa@civil.kyushu-u.ac.jp \\ Masaki Yokota, Kyushu Sangyo University, m.yokota@ip.kyusan-u.ac.jp \\ Yukifumi Ikki, Ministry of Land, Infrastructure, Transport and Tourism, ikki-y89ua@mlit.go.jp \\ Masaru Takayama, Ministry of Land, Infrastructure, Transport and Tourism, takayama-m899v@mlit.go.jp
}

\section{INTRODUCTION}

The Kanmon waterway is one of the most important international routes in Japan. The waterway is in the Kanmon Strait, which is remarkably narrow and meandering considerably, and the tidal current is rapid and complicated in several places. In the waterway, sand waves, which may hamper the ship navigation, develop on the bottom at some places (Figure 1). The dredging is indispensable to the maintenance of required water depth in the waterway. In this study, for the purpose of accumulating useful knowledge for the efficient maintenance of the Kanmon waterway, the characteristics and cause of the sand waves in the waterway were investigated.

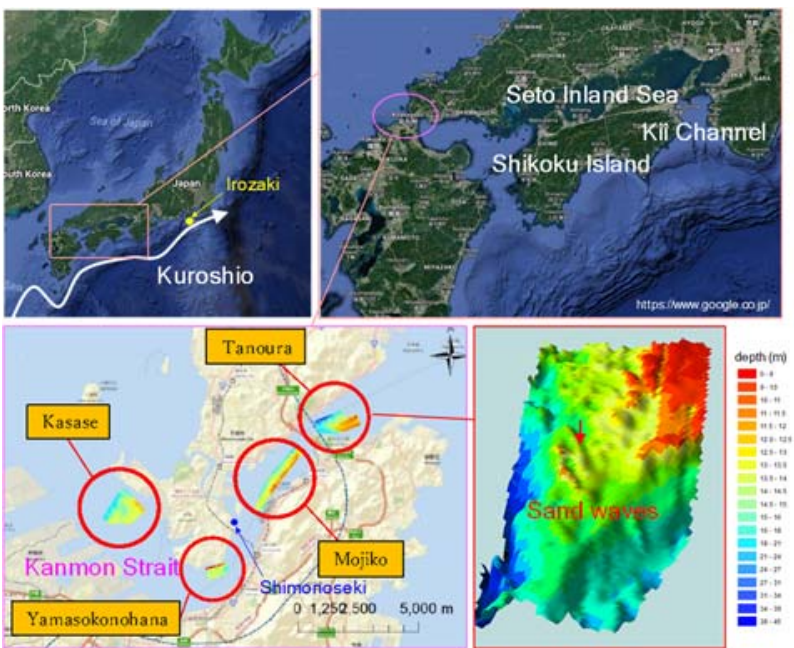

Figure 1 - Location of the Kanmon waterway and sand waves in Tanoura area

\section{SAND WAVES IN THE KANMON WATERWAY}

Figure 1 shows the sand waves in Tanoura area where the sand waves are formed remarkably. MLIT (Ministry of Land, Infrastructure, Transport and Tourism) has been continuing the yearly survey of bathymetry in the whole waterway since 1974. Especially, at four areas where the sand waves are formed frequently, the survey has been conducted several times a year. From the sounding data, the characteristics of the sand waves, i.e. sizes, moving velocities, occurrence frequencies, etc. were clarified. In Tanoura area, for example, the moving velocity of the sand waves is about 0.2 to $0.8 \mathrm{~m} / \mathrm{day}$, and its formation cycle is approximately 20 to 45 months.

\section{DISCUSSION ON CAUSE OF SAND WAVES}

It would be supposed that tidal currents are main cause of the development of sand waves. The continuous tidal current observation, however, are not conducted in the Kanmon Strait. Thus, the tidal change data which are continually obtained at several points in the strait were investigated instead of the tidal currents. As shown in Figure 2, it was found that the water depth change due to the sand waves has relatively high correlation with the long-term fluctuation of sea level departure.

Next, the characteristics and cause of the long-term fluctuation of sea level departure in the Kanmon Strait were investigated. The results showed that the amplitude of the long-term fluctuation of the sea level departure decreases from the Kii Channel to the Kanmon Strait through the Seto Inland Sea. Furthermore, it was found that there are high correlations between the path variation of Kuroshio, which is a major warm current flowing along the pacific coasts of Japan, and the long-term fluctuations of the sea level departure at many places, especially around Shikoku Island.

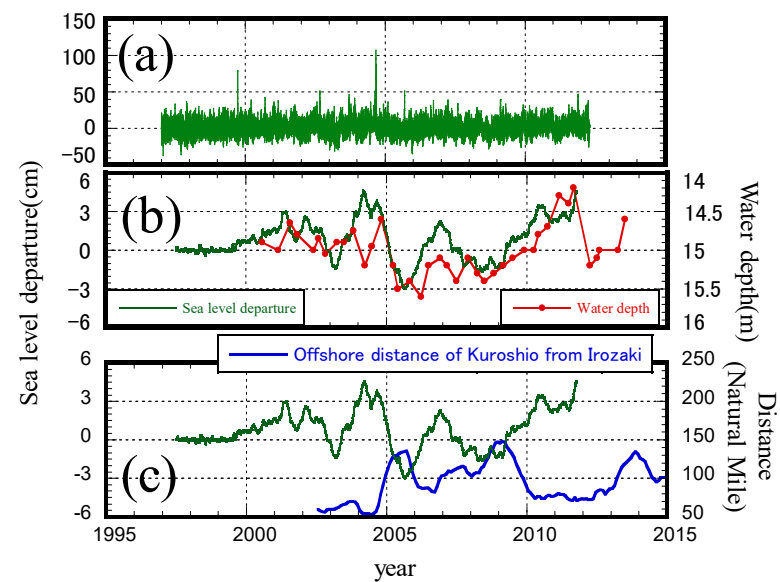

Figure 2 - (a) Sea level departure obtained from tidal change at Shimonoseki, (b) Long-term fluctuation(one year moving average) of the sea level departure at Shimonoseki and a temporal water depth change on sand waves in Tanoura(the location is indicated by a red arrow in Fig. 1), the correlation coefficient is 0.70 , (c) Long-term fluctuation of the sea level departure at Shimonoseki and Long term fluctuation of offshore distance Kuroshio at Irozaki, the correlation coefficient is -0.67

\section{CONCLUSIONS}

This study investigated the characteristics and cause of sand waves in the Kanmon waterway. The results imply that the long-term fluctuation of tidal currents accompanied by the long-term fluctuation of sea level departure affects the development of sand waves, and that the Kuroshio path variation causes the long-term fluctuation of sea level departure in the Kanmon waterway. 